\title{
Evaluation Techniques For Cooperative Learning
}

Denise M. Woods, Ph.D., Purdue University Calumet, USA

Kuan-Chou Chen, Ph.D., Purdue University Calumet, USA

\begin{abstract}
Cooperative learning is an instructional model in which students work together toward a common goal. Research has clearly shown that cooperation results in higher levels of achievement. Although students may be a part of a cooperative learning environment, they are also responsible for their own individual achievement. This makes student evaluations a challenge because you are evaluating individual as well as team effort. This paper will review the alternatives for assessing the participation of individual student on a team as well as discuss the cases in which each approach was used. It identifies the positives and negatives of each approach.
\end{abstract}

Keywords: Cooperative learning, Evaluation techniques; Management Information Systems

\section{INTRODUCTION}

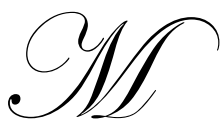

any courses taught in the Management Information Systems (MIS) curriculum utilize the cooperative teaching strategy. Students are combined into small teams and utilize a variety of activities to improve their learning. Each team member is responsible to learn what is being taught on his/her own. Additionally, students are responsible to help teammates learn. The atmosphere created in a cooperative learning environment is one that promotes achievement in all students. Research has shown that a cooperative learning environment: promotes student learning and academic achievement, increases student retention of information, helps students to further develop their social skills, and results in a higher level of course satisfaction.

In our use of cooperative learning in the MIS courses, we stress individual as well as group accountability. Teams are responsible to complete assignments as a group, and although the team receives one grade for any assignment, individual participation must also be assessed. Assessing the participation of individual students on a team can be challenge of using the cooperative learning strategy.

In our Management Information Systems (MIS) program, we utilize cooperative learning in many classes. We have tried different forms of evaluation in these courses. This paper discusses our successes and our failures with evaluation techniques as they relate to both individual and team assignments.

\section{COOPERATIVE LEARNING}

\section{What is cooperative learning?}

Instructors are sometimes mistaken that they are using the cooperative learning model. They oftentimes feel that just telling students to "work together" or putting groups of students in teams for assignments means that they are utilizing cooperative learning techniques. "Merely because students work in small groups does not mean that they are cooperating to ensure their own learning and the learning of all others in their group" (Johnson, Johnson, and Holubec, 1993). There is a great difference between having students work in groups and structuring the groups to work in a cooperative effort. Instructors break students into teams for class discussion. They may also have students work in temporary teams to work on assignments related to the lecture. This sort of ad hoc team is not what cooperative learning is all about though. 
"A group of students sitting at the same table doing their own work, but free to talk with each other as they work, is not structured to be a cooperative group, as there is no positive interdependence" (Johnson \& Johnson, 1994, p. 1). According to Johnson \& Johnson (1994), five conditions must be met in order for a cooperative learning effort to be more productive than competitive or individualistic methods:

1. Clearly perceived positive interdependence

2. Considerable promotive (face-to-face) interaction

3. Clearly perceived individual accountability and personal responsibility to achieve the group's goals

4. $\quad$ Frequent use of the relevant interpersonal and small-group skills

5. Frequent and regular group processing of current functioning to improve the group's future effectiveness (Johnson \& Johnson, 1994)

Without these five conditions, the environment is not conducive to a cooperative learning experience. CAI Cui-yun cites specific conditions for cooperative learning as well. Both lists of conditions are similar.

"In a broad sense, cooperative learning refers to a relationship in a group of students that requires cooperative efforts. Those conditions are including clearly perceived positive interdependence (a sense of sink or swim together), clearly perceived individual accountability and personal responsibility to achieve the group's goals (each of us has to contribute and learn), frequent use of the relevant interpersonal and small-group skills (communication, trust, leadership, decision making, and conflict resolution), considerable promotive (face-to-face) interaction and frequent and regular group processing of current functioning to improve the group's future effectiveness (reflecting on how well the team is functioning and how to function even better). Cooperative learning focuses on how students should interact with each other as they learn and the skills needed to interact effectively" (CAI Cui-yun, 2007, p. 30).

In most college classrooms in the past, the instructor was a lecturer. The instructor dispensed the information to the students, students worked individually on homework assignments or projects, and the instructor utilized assessment techniques to determine the level of learning that took place. Certainly, this was an effective model for many years and for many students. Students did achieve learning with this model, but research shows that cooperative learning results in an even higher achievement level.

The cooperative learning model, in fact, redefines the role of the educator. With this type of instruction, the teacher acts more as a facilitator, rather than as a lecturer. With cooperative learning, students are encouraged to work together to discover the knowledge and to help each other learn (Walters, 2000). The environment of a cooperative learning classroom is less competitive (i.e., students competing against each other for grades) and more cooperative (i.e., students work together toward a common goal).

\section{Why MIS courses use cooperative learning?}

There are two main reasons why the cooperative learning model should be used in MIS courses. First, the specific areas of MIS involves quite complex and project-oriented activities. Complex concepts can be difficult for students to learn on their own. Additionally, large semester projects can be difficult for students to complete on their own. It is helpful for teams of students to work together to learn. Effectively teaching students complex concepts such as database design, normalization, or project management skills and techniques can be difficult. Having teams of students work on normalizing a database together can be a very rewarding experience for both the students and the instructor An instructor has many ways to present material in a lecture, but students may have different, sometimes more effective, ways to express the same concepts to each other. "Cooperative leaning activities can be used to supplement textbook instruction by providing students with opportunities to practice newly introduced or to review skills and concepts. Teachers can use cooperative learning activities to help students make connections between the concrete and abstract level of instruction through peer interactions and carefully designed activities" (Rivera, 1996). As mentioned above, cooperative learning is especially important when the task is complex or conceptual, or when problem solving is desired. Most, if not all, of MIS projects are problem solving in nature. An MIS department's main goal is to solve business problems by effectively utilizing system solutions. Installing an Enterprise Resource Planning (ERP) system solution is the way that companies are making information available to 
those who need it. An ERP installation is complex by nature because it targets all functional areas within a company.

The second reason why it is important for MIS courses to use cooperative learning is that there are very few MIS projects in the business world that are done by individuals. Almost all MIS projects, particularly because of their magnitude and far-reaching platform, require the work of teams of employees. Diverse teams are very common in the MIS world because of the need for user input to projects. For example, you may have an MIS project team that includes an industrial engineer, a warehouse manager, and a packing clerk working together with the MIS professionals. It is very important for MIS majors to understand that their work life outside of school will include working closely with diverse teams of people on projects. We are not born knowing instinctively how to interact effectively with other people. Effective interpersonal and small-group skills are not things that come naturally to most of us (Johnson \& Johnson, 1994). "Students who have had 12-20 years of cooperative learning and who have had opportunities to work cooperatively with students who vary in ability, ethnicity, gender, and so forth will be better able to build positively interdependent relationships than will students who had had 12-20 years of competitive and individualistic learning" (Johnson \& Johnson, 1994, p. 8). It is up to us, as educators, to provide that environment to our students in which their social skills can be honed. Putting students in diverse teams is helpful not just for their academic lives but for their future work lives as well.

In our MIS courses, we use cooperative learning for three general areas: case study analyses, quizzes, and semester projects. In each case, the instructor clearly defines the goals of the team effort. The area most like that which students will encounter in business in the future is the semester project. Semester projects are what we will concentrate on in the remainder of this paper.

\section{Cooperative learning format}

According to Walters (2000), there are four cooperative learning models.

1. Student Team learning (STL) - this is a model in which teams of students earn rewards if they improve their own scores. Students also earn rewards for improving members of the team's scores in general.

2. Learning Together - this is the model in which a single product is turned in, and the team of students receives a group grade. The emphasis in this model is on team-building activities.

3. Jigsaw - this is a model in which students are formed into groups with individual students learning one segment of material, which they then teach to the other students in the group. One student "expert" from each team also meet to discuss the material and to help each other formulate effective teaching techniques.

4. Group Investigation - in this model, students form their own two- to six-person teams, teams select subtopics from a class-wide unit of instruction, and teams of students develop group reports based on that subtopic.

The model that we utilize most often in many MIS courses for semester-long projects is the Learning Together model. The semester project is quite large, involves a team of four to five students, and the team receives a single grade for the project.

\section{CASE - APPROACHES FOR EVALUATIONS}

"The essential component of cooperative learning is group processing. Effective group work is influenced by whether or not groups reflect on (i.e., process) how well they are functioning. A proves is an identifiable sequence of events taking place over time, and process goals refer to the sequence of events instrumental in achieving outcome goals" (CAI Cui-yun, 2007).

As mentioned above, we use the cooperative learning model in our MIS courses that have semester-long projects. One such class is the Project Management course. Our goal was to effectively and fairly evaluate the team as well as each individual student on the team. We took a self-evaluation approach to finding an effective evaluation technique to apply to these semester-long projects. 


\section{Evaluation attempt}

In our first attempt at an effective evaluation process, we solicited input from students on the contribution of each member of the team. We had students complete an evaluation form (see Appendix) for every other member team. The evaluation was done by each student at the end of the semester and handed in to the instructor.

This approach allowed students to approve or counter the evaluation of their efforts. This approach made students more aware of applying fairness to the process. Students who were less than honest about their own contribution were subject to an approval process by the other students. This is fairer to the students because it allows them the opportunity to make corrective action through the remainder of the project if they have problems. The approach also triggers communication between team members where it might be lacking. We have found this third evaluation approach to work successfully.

\section{CONCLUSIONS}

Cooperative learning is a popular instructional arrangement for teaching Management Information Systems (MIS) to students to achieve higher levels of knowledge. Coupled with direct instruction, cooperative learning holds great promise as a supplement to textbook instruction by providing students with opportunities to help students learn to work in teams, which will be very important in their futures, especially valuable for complex concepts or projectbased tasks. Evaluating cooperative learning projects can be difficult. However, carefully constructed learning assessment method, using the model presented in this paper can offer students with rich learning opportunities in MIS instruction.

\section{REFERENCES}

1. Cai Cui-yun, IEDC Method: A New Approach to Promote Students' Communicative Competence, USChina Education Review, Vol. 4, No. 5, 2007.

2. Johnson, David W. \& Johnson, Roger T., An Overview of Cooperative Learning, Creativity and Collaborative Learning, Brookes Press, Baltimore, 1994.

3. Johnson, David W. \& Johnson, Roger T., Cooperative Learning and Assessment, Cooperative Learning, JALT Applied Materials, 1999.

4. Jones, KaJones, \& Jennifer L., College Quarterly, Vol. 11, No. 1, 2008.

5. Panitz, Theodore \& Panitz, Patricia, Assessing Students and Yourself Using the One Minute Paper and Observing Students Working Cooperatively, 1999.

6. Rivera, Diane Pedrotty, Using Cooperative Learning to Teach Mathematics to Students with Learning Disabilities, LD Forum: Council for Learning Disabilities, Spring, 1996.

7. Stahl, Robert J., The Essential Elements of Cooperative Learning in the Classroom, Educational Research Information Center, 2000.

8. Walters, Laurel Shaper, Putting Cooperative Learning to the Test, Harvard Education Letter, May/June, Vol. 16, No. 3, 2000. 


\section{APPENDIX}

MGMT 486/ 590 Final Project

Personal Time Sheet

Team name:

Print your name:

Phase 1:

Out of $100 \%$ in this final project, what percentage did you contribute in the following:

\begin{tabular}{|c|c|c|c|c|}
\hline $\begin{array}{c}\text { Team meeting } \\
20 \%\end{array}$ & $\begin{array}{c}\text { Communication } \\
20 \%\end{array}$ & $\begin{array}{c}\text { Complete Task on time } \\
20 \%\end{array}$ & $\begin{array}{c}\text { Collecting Data } \\
20 \%\end{array}$ & $\begin{array}{c}\text { Writing } \\
20 \%\end{array}$ \\
\hline & & & & \\
& & & & \\
\hline
\end{tabular}

Your Signature:

Team member signature:

Team member signature:

Team member signature:

Team member signature: 


\section{NOTES}

